CLINICAL STUDY

\title{
Increased serum concentrations of macrophage inhibitory cytokine- 1 in patients with obesity and type 2 diabetes mellitus: the influence of very low calorie diet
}

\author{
Ivana Dostálová ${ }^{1}$, Tomáš Roubíček ${ }^{1}$, Markéta Bártlová ${ }^{1}$, Miloš Mráz ${ }^{1}$, Zdena Lacinová ${ }^{1}$, Denisa Haluzíková ${ }^{1,2}$, \\ Petra Kaválková ${ }^{1}$, Martin Matoulek ${ }^{1}$, Mojmír Kasalický ${ }^{3}$ and Martin Haluzík ${ }^{1}$ \\ ${ }^{1}$ 3rd Department of Medicine, ${ }^{2}$ Department of Sports Medicine and ${ }^{3}$ Department of Surgery, 1st Faculty of Medicine, Charles University and General \\ University Hospital, U Nemocnice 1, 128 OO Prague 2, Czech Republic
}

(Correspondence should be addressed to M Haluzik; Email: mhalu@lf1.cuni.cz)

\begin{abstract}
Objective: Macrophage inhibitory cytokine-1 (MIC-1) is a novel regulator of energy homeostasis. We explored whether alterations in MIC-1 levels contribute to metabolic disturbances in patients with obesity and/or obesity and type 2 diabetes mellitus (T2DM).

Design: We measured serum MIC-1 levels and its mRNA expression in subcutaneous and visceral adipose tissue of 17 obese nondiabetic women, 14 obese women with T2DM and 23 healthy lean women. We also explored the relationship of MIC-1 with anthropometric and biochemical parameters and studied the influence of 2-week very low calorie diet (VLCD) on serum MIC-1 levels.

Methods: Serum MIC-1 levels were measured by ELISA and its mRNA expression was determined by RT-PCR.

Results: Both obese and T2DM group had significantly elevated serum MIC-1 levels relative to controls. T2DM group had significantly higher serum MIC-1 levels relative to obese group. Serum MIC-1 positively correlated with body weight, body fat, and serum levels of triglycerides, glucose, HbAlc, and C-reactive protein and it was inversely related to serum high-density lipoprotein cholesterol. Fat mRNA MIC-1 expression did not significantly differ between lean and obese women but it was significantly higher in subcutaneous than in visceral fat in both groups. VLCD significantly increased serum MIC-1 levels in obese but not T2DM group.

Conclusion: Elevated MIC-1 levels in patients with obesity are further increased by the presence of T2DM. We suggest that in contrast to patients with cancer cachexia, increased MIC-1 levels in obese patients and diabetic patients do not induce weight loss.
\end{abstract}

European Journal of Endocrinology 161 397-404

\section{Introduction}

Macrophage inhibitory cytokine-1 (MIC-1) is a member of the transforming growth factor- $\beta$ superfamily (1-3). It is expressed in activated macrophages (1), placenta and prostate, and to a lesser extent in the liver, kidney and brain $(4,5)$. Significant amounts of MIC-1 are released into the circulation suggesting that it can also act as an endocrine factor (6).

Increased concentrations of MIC-1 were found in patients with chronic inflammatory states such as rheumatoid arthritis (7) and in many types of cancer (8-10). MIC-1 was also identified as a predictor of cardiovascular events in a cohort of previously healthy women $(11,12)$ and as an early mediator of the injury response in kidney and lung (13). Recently, a key role of increased MIC-1 concentrations in the induction of cancer-related anorexia and weight loss in animals and humans was described (14).

Previous findings suggested an important role for MIC-1 in inflammatory and atherosclerotic processes and body weight regulation making it a possible etiopathogenetic candidate and/or metabolic marker of obesity and its associated co-morbidities such as insulin resistance or type 2 diabetes mellitus (T2DM). However, to our best knowledge no information about possible changes of circulating levels of MIC-1 in patients with obesity or in patients with the combination of obesity and T2DM is available. To this end, we measured fasting serum levels of MIC-1 in nondiabetic obese women, in obese women with T2DM, and in healthy normal-weight women. We also assessed 
MIC-1 mRNA expression in subcutaneous and visceral fat and studied how 2 weeks of very low calorie diet (VLCD) affect its circulating concentrations in obese and diabetic patients.

\section{Subjects and methods}

\section{Study subjects}

Written informed consent was signed by all participants before being enrolled into the study. The study was approved by the Human Ethical Review Committee, 1st Faculty of Medicine and General University Hospital, Prague, Czech Republic and was performed in accordance with the guidelines proposed in the Declaration of Helsinki.

Overall, 17 obese women without T2DM (obese; age: $45.9 \pm 3.2$ years, body mass index (BMI): 50.4 $\pm 2.6 \mathrm{~kg} / \mathrm{m}^{2}$, body fat content (\%BF): $54.4 \pm 1.7 \%$ ), 14 obese women with T2DM (age: $56.1 \pm 2.3$ years, BMI: $50.9 \pm 2.5 \mathrm{~kg} / \mathrm{m}^{2}$, \%BF: $\left.55.2 \pm 1.7 \%\right)$ and 23 agematched healthy control women (age: $45.1 \pm 2.5$, BMI: $23.3 \pm 0.4 \mathrm{~kg} / \mathrm{m}^{2}$, \%BF: $27.3 \pm 1.9 \%$ ) were included in the study. Body weight of all study participants remained stable for at least 3 months before the beginning of the study. Women with T2DM were treated by diet or oral antidiabetics at the time of the study. None of the studied subjects suffered from thyroid disorder and/or acute infectious disease. None of the studied subjects had malignant tumor. All subjects included in the study were nonsmokers and had no allergies. Healthy women had no history of obesity or malnutrition, hypertension, and/or gastrointestinal disease. Blood tests confirmed normal blood count, liver, and renal functions. All subjects were asked to fast and drink only water on the night prior to the study.

All obese women without T2DM and all obese women with T2DM underwent a 2-week VLCD program with energy content of $2200 \mathrm{~kJ} /$ day $(550 \mathrm{kcal} /$ day $)$. All of the patients were hospitalized in the 3rd Department of Medicine, General University Hospital, Prague, Czech Republic.

\section{MIC-1 mRNA expression sub-study}

The mRNA expression of MIC-1 in visceral and subcutaneous fat was measured in another patients' population. Fat samples were obtained from 12 nondiabetic obese women undergoing gastric banding surgery for the 3rd grade obesity (age: $39.9 \pm 3.5$ years, BMI: 43.2 $\pm 0.8 \mathrm{~kg} / \mathrm{m}^{2}$ ) and from 12 lean control women (age: $49.5 \pm 3.8$ years, BMI: $23.6 \pm 0.6 \mathrm{~kg} / \mathrm{m}^{2}$ ) undergoing elective cholecystectomy.

\section{Anthropometric examination, blood, and tissue sampling}

All patients with obesity/T2DM were examined twice: at a basal state before the beginning of any treatment and after 2 weeks of VLCD while normal-weight healthy women were examined only once. All subjects were measured and weighed and their BMI was calculated. BF content was estimated by bioimpedance analysis (Bodystat 1500, Bodystat Ltd, Douglas, Isle of Man, UK). Blood samples for MIC-1, insulin, and biochemical parameters were withdrawn between 0700 and $0800 \mathrm{~h}$ after $12 \mathrm{~h}$ of overnight fasting. Blood samples were separated by centrifugation for $10 \mathrm{~min}$ at $1000 \boldsymbol{g}$ within 30 min from blood collection. Serum was subsequently stored in aliquots at $-80{ }^{\circ} \mathrm{C}$ until further analysis.

Paired samples of subcutaneous and visceral adipose tissue from lean and obese women were collected at the beginning of surgery (gastric banding in obese and elective cholecystectomy in control subjects respectively). Approximately $100 \mathrm{mg}$ of adipose tissue was collected to $1 \mathrm{ml}$ of RNA stabilization reagent (RNAlater, Qiagen) and stored at $-80{ }^{\circ} \mathrm{C}$ until further analysis.

\section{Hormonal and biochemical assays}

Serum MIC-1 concentrations were measured by commercial ELISA kit (Biovendor, Brno, Czech Republic), following the manufacturer's instructions. Sensitivity was $10 \mathrm{pg} / \mathrm{ml}$ and the intra- and interassay variability of the kit was 3.7 and $<10 \%$ respectively. Serum insulin

Table 1 Anthropometric, hormonal, and biochemical characteristics of healthy control women, obese women without type 2 diabetes mellitus (T2DM), and obese women with T2DM. All characteristics of the patients are pre-treatment values.

\begin{tabular}{|c|c|c|c|}
\hline & Controls $(n=23)$ & Obese $(n=17)$ & T2DM $(n=14)$ \\
\hline Age (years) & $45.1 \pm 2.5$ & $45.9 \pm 3.2$ & $56.1 \pm 2.3$ \\
\hline Body mass index $\left(\mathrm{kg} / \mathrm{m}^{2}\right)$ & $23.3 \pm 0.4$ & $50.4 \pm 2.6^{*}$ & $50.9 \pm 2.5^{\star}$ \\
\hline Body fat content (\%) & $27.3 \pm 1.9$ & $54.4 \pm 1.7^{*}$ & $55.2 \pm 1.7^{\star}$ \\
\hline Cholesterol (mmol/l) & $5.1 \pm 0.2$ & $4.9 \pm 0.2$ & $4.5 \pm 0.3$ \\
\hline Triglycerides $(\mathrm{mmol} / \mathrm{l})$ & $1.0 \pm 0.1$ & $1.5 \pm 0.1^{*}$ & $2.2 \pm 0.4^{\star}$ \\
\hline HDL-cholesterol $(\mathrm{mmol} / \mathrm{l})$ & $1.6+0.1$ & $1.2+0.1^{*, \dagger}$ & $0.9+0.1^{*}$ \\
\hline LDL-cholesterol (mmol/l') & $3.1 \pm 0.2$ & $3.0 \pm 0.2$ & $2.7 \pm 0.2$ \\
\hline Fasting qlucose $(\mathrm{mmol} / \mathrm{l})$ & $4.4+0.3$ & $5.1+0.2^{\dagger}$ & $9.9+1.1^{*}$ \\
\hline HbAlc (\%) & $3.6 \pm 0.1$ & $4.0 \pm 0.2^{\dagger}$ & $7.7 \pm 0.9^{*}$ \\
\hline Fasting insulin (mIU/l) & $8.5+1.2$ & $13.0+1.7$ & $19.8 \pm 4.8^{\star}$ \\
\hline C-reactive protein (mg/l) & $5.3+0.8$ & $14.2+2.2^{*}$ & $13.2+3.5^{*}$ \\
\hline HOMA-IR & $1.4 \pm 0.2$ & $3.0 \pm 0.4^{*, \dagger}$ & $8.3 \pm 1.9^{\star}$ \\
\hline
\end{tabular}

Results are means \pm S.E.M. ${ }^{*} P<0.05$ versus controls; ${ }^{\dagger} P<0.05$ versus T2DM. 
Table 2 Baseline characteristics of healthy control women and obese women included in macrophage inhibitory cytokine-1 expression sub-study.

\begin{tabular}{lcr}
\hline & $\begin{array}{c}\text { Controls } \\
(n=12)\end{array}$ & $\begin{array}{c}\text { Obese } \\
(n=12)\end{array}$ \\
\hline Age (years) & $49.5 \pm 3.8$ & $39.9 \pm 3.5$ \\
Body mass index $\left(\mathrm{kg} / \mathrm{m}^{2}\right)$ & $23.6 \pm 0.6$ & $43.2 \pm 0.8^{*}$ \\
Cholesterol $(\mathrm{mmol} / \mathrm{l})$ & $4.8 \pm 0.24$ & $4.5 \pm 0.21$ \\
Triglycerides $(\mathrm{mmol} / \mathrm{l})$ & $1.2 \pm 0.22$ & $1.7 \pm 0.36$ \\
Fasting glucose $(\mathrm{mmol} / \mathrm{l})$ & $4.6 \pm 0.24$ & $5.0 \pm 0.37$ \\
Fasting insulin $(\mathrm{mlU} / \mathrm{l})$ & $10.7 \pm 2.30$ & $14.4 \pm 1.47$ \\
HOMA-IR & $2.2 \pm 0.63$ & $3.6 \pm 1.41^{*}$ \\
C-reactive protein $(\mathrm{mg} / \mathrm{l})$ & $7.9 \pm 2.52$ & $17.6 \pm 3.24^{*}$ \\
\hline
\end{tabular}

Results are means \pm S.E.M. ${ }^{*} P<0.05$ versus controls.

concentrations were measured by commercial RIA kit (Cis Bio International, Gif-sur-Yvette Cedex, France). Sensitivity was $2.0 \mu \mathrm{IU} / \mathrm{ml}$ and the intra- and interassay variability was $<5$ and $<9 \%$ respectively. Biochemical parameters were measured in the Department of Biochemistry of General University Hospital by standard laboratory methods.

Homeostasis model assessment of insulin resistance (HOMA-IR) index was calculated as previously described using the following formula: fasting serum insulin $(\mathrm{mIU} / \mathrm{l}) \times$ fasting serum glucose $(\mathrm{mmol} / \mathrm{l}) / 22.5$ (15).

\section{Determination of mRNA expression}

Total RNA was extracted from 60 to $80 \mathrm{mg}$ of subcutaneous and visceral adipose tissue by homogenization using MagNA lyser (Roche Diagnostic, $\mathrm{GmbH}$ ) instrument and following isolation of RNA on automatic isolator MagNA Pure Compact (Roche Diagnostics, $\mathrm{GmbH}$ ) using MagNA Pure Compact RNA Isolation kit (Roche Diagnostics, $\mathrm{GmbH}$ ). The integrity of the RNA was checked by visualization of $18 \mathrm{~S}$ and $28 \mathrm{~S}$ ribosomal bands on $1 \%$ agarose gel with ethidium bromide. Concentration and purity of RNA were determined by spectrophotometer (BioPhotometr Eppendorf AG, Hamburg, Germany).

For RT, $0.05 \mu \mathrm{g}$ of total RNA was used to synthesize the first strand cDNA using the oligo(dT) primers following the instructions of the RevertAid First Strand cDNA
Synthesis kit (Fermentas Life Science, Vilnius, Lithuania). cDNA was used for determination of gene expression of MIC-1 and 18S rRNA by method real-time PCR performed on ABI PRISM 7500 instrument (Applied Biosystems, Foster City, CA, USA) using TaqMan Universal PCR Master Mix, NO AmpErase UNG, and specific TaqMan gene expression assays (Applied Biosystems).

All PCRs for each gene were amplified separately. Controls with no template cDNA were performed with each assay and all samples were run at least in duplicates. The increase in fluorescence was measured in real-time and data were obtained as threshold cycle $\left(C_{\mathrm{T}}\right)$ values. Results were normalized to $18 \mathrm{~S}$ rRNA. Relative gene expression of genes was calculated using

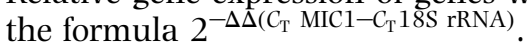

\section{Statistical analysis}

The statistical analysis was performed on SigmaStat software (Jandel Scientific, San Rafael, CA, USA). The results are expressed as means \pm s.E.M. Comparisons of MIC-1 levels, anthropometric, biochemical, and hormonal parameters among the three groups studied (obese, T2DM, controls) were evaluated by one-way ANOVA followed by Holm-Sidak or Dunn's test as appropriate. The comparison of anthropometric and biochemical parameters, and MIC-1 levels before and after VLCD was evaluated by Wilcoxon Sum Rank Test. Pearson or Spearman correlation tests were used to calculate the relationships between MIC-1 levels and other parameters. Multiple regression analysis was used to show the independent relationship of MIC-1 with other parameters. A $P$ value $<0.05$ denoted statistical significance.

\section{Results}

\section{Anthropometric, hormonal, and biochemical characteristics of the study subjects}

The study groups were age-matched. Both obese and T2DM groups had markedly increased BMI and BF content as compared with control group (Table 1). BMI and BF content of obese and T2DM group did not

Table 3 The influence of 2 weeks of very low calorie diet (VLCD) on anthropometric and biochemical parameters in obese women without type 2 diabetes mellitus (T2DM) and obese women with T2DM.

\begin{tabular}{|c|c|c|c|c|}
\hline & \multicolumn{2}{|c|}{ Obese $(n=17)$} & \multicolumn{2}{|c|}{ T2DM $(n=14)$} \\
\hline & Pre-VLCD & Post-VLCD & Pre-VLCD & Post-VLCD \\
\hline BMI $\left(\mathrm{kg} / \mathrm{m}^{2}\right)$ & $50.4 \pm 2.6$ & $48.0 \pm 2.5^{\dagger}$ & $50.9 \pm 2.5$ & $47.8 \pm 2.3^{\dagger}$ \\
\hline Body weight (\%) & $146.5 \pm 9.3$ & $140.2 \pm 8.8^{\dagger}$ & $135.6 \pm 6.6$ & $127.4 \pm 6.0^{\dagger}$ \\
\hline Cholesterol $(\mathrm{mmol} / \mathrm{l})$ & $4.9 \pm 0.2$ & $4.1 \pm 0.3^{\dagger}$ & $4.5 \pm 0.3$ & $4.1 \pm 0.2^{\dagger}$ \\
\hline Triglycerides $(\mathrm{mmol} / \mathrm{l})$ & $1.5 \pm 0.1$ & $1.3 \pm 0.1^{\dagger}$ & $2.2 \pm 0.4$ & $1.4 \pm 0.2^{\dagger}$ \\
\hline Fasting glucose $(\mathrm{mmol} / \mathrm{l})$ & $5.1 \pm 0.2$ & $4.9 \pm 0.2$ & $9.9 \pm 1.1$ & $7.3 \pm 0.8^{\dagger}$ \\
\hline Fasting insulin (mIU/l) & $13.0 \pm 1.7$ & $12.0 \pm 1.5$ & $19.8 \pm 4.8$ & $12.1 \pm 1.1^{\dagger}$ \\
\hline CRP $(\mathrm{mg} / \mathrm{l})$ & $14.2 \pm 2.2$ & $5.8 \pm 1.3^{\dagger}$ & $13.2 \pm 3.5$ & $7.1 \pm 2.4^{\dagger}$ \\
\hline HOMA-IR & $3.0 \pm 0.4$ & $2.6 \pm 0.4$ & $8.3 \pm 1.9$ & $4.1 \pm 0.8^{\dagger}$ \\
\hline
\end{tabular}

Results are means \pm S.E.M. ${ }^{\dagger} P<0.05$ versus before VLCD. 


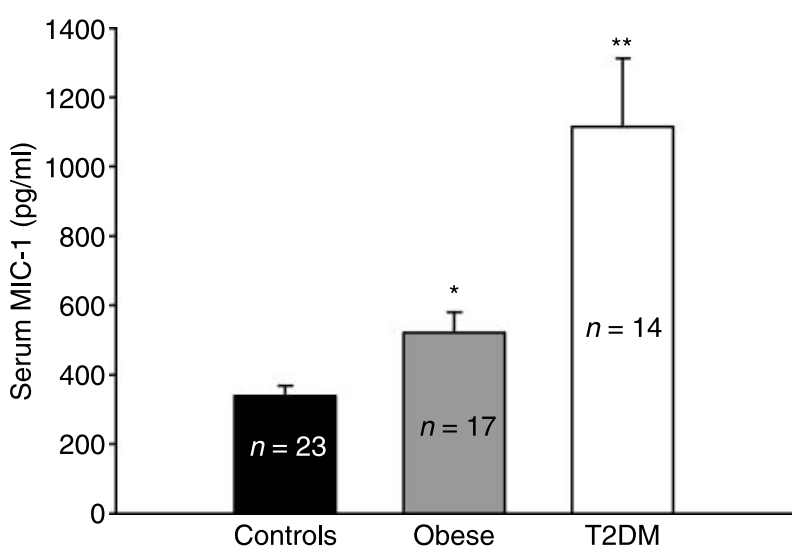

Figure 1 Serum concentrations of macrophage inhibitory cytokine-1 (MIC-1; pg/ml) in healthy control women $(n=23)$, obese women without type 2 diabetes (obese; $n=17$ ), and in obese women with type 2 diabetes (T2DM; $n=14$ ). Values are means \pm S.E.M. Statistical significance is from ANOVA. ${ }^{*} P<0.05$ vs controls, ${ }^{* *} P<0.05$ vs obese

significantly differ. Fasting serum levels of total cholesterol and low-density lipoprotein-cholesterol did not significantly differ between the groups studied. Fasting serum levels of triglycerides and C-reactive protein (CRP) were significantly increased in both obese and T2DM group as compared with control group. Fasting serum glucose and HbAlc levels were significantly higher in T2DM group as compared with obese and control group. Fasting serum insulin levels were significantly increased in T2DM group relative to control group and tended to be increased in obese group relative to control group, but the difference did not reach statistical significance. Fasting serum high-density lipoprotein (HDL)-cholesterol levels were significantly lower in both the obese and diabetic group relative to control groups. HDL-cholesterol in T2DM was significantly lower than in the obese group (Table 1). Baseline characteristics of the subjects included in the mRNA expression sub-study are shown in Table 2.

The influence of 2 weeks of VLCD on anthropometric, hormonal, and biochemical parameters in the obese and T2DM group is shown in Table 3. Body weight of both obese and T2DM patients significantly decreased after 2 weeks of VLCD. VLCD significantly reduced serum levels of total cholesterol, triglycerides, and CRP in both the obese and T2DM group. VLCD significantly reduced serum glucose and insulin levels, and HOMA index in T2DM group only (Table 3).

\section{Serum levels of MIC-1 in obese women without T2DM, obese women with T2DM, and normal-weight women and the changes after 2-week VLCD}

Fasting serum MIC-1 concentrations were significantly increased in both the obese and T2DM group as compared with control group. Serum MIC-1 levels were significantly higher in T2DM group relative to obese group (Fig. 1). Two-week VLCD significantly increased serum MIC-1 levels in the obese group but it did not significantly affect MIC-1 concentrations in T2DM group (Fig. 2A and B).

\section{Relationship of MIC-1 with other studied parameters}

The relationship of serum MIC-1 levels with other studied parameters was calculated in the combined population of all three groups (obese, T2DM, and controls; Table 4) and in the population of obese women (both obese and T2DM included) both before and after VLCD (Table 4). In the combined population of all three groups, serum MIC-1 significantly positively correlated with BMI, BF content, serum triglycerides, serum glucose, serum HbAlc, and serum CRP and was inversely related to serum HDL-cholesterol (Table 4). Multiple regression analysis showed that serum glucose
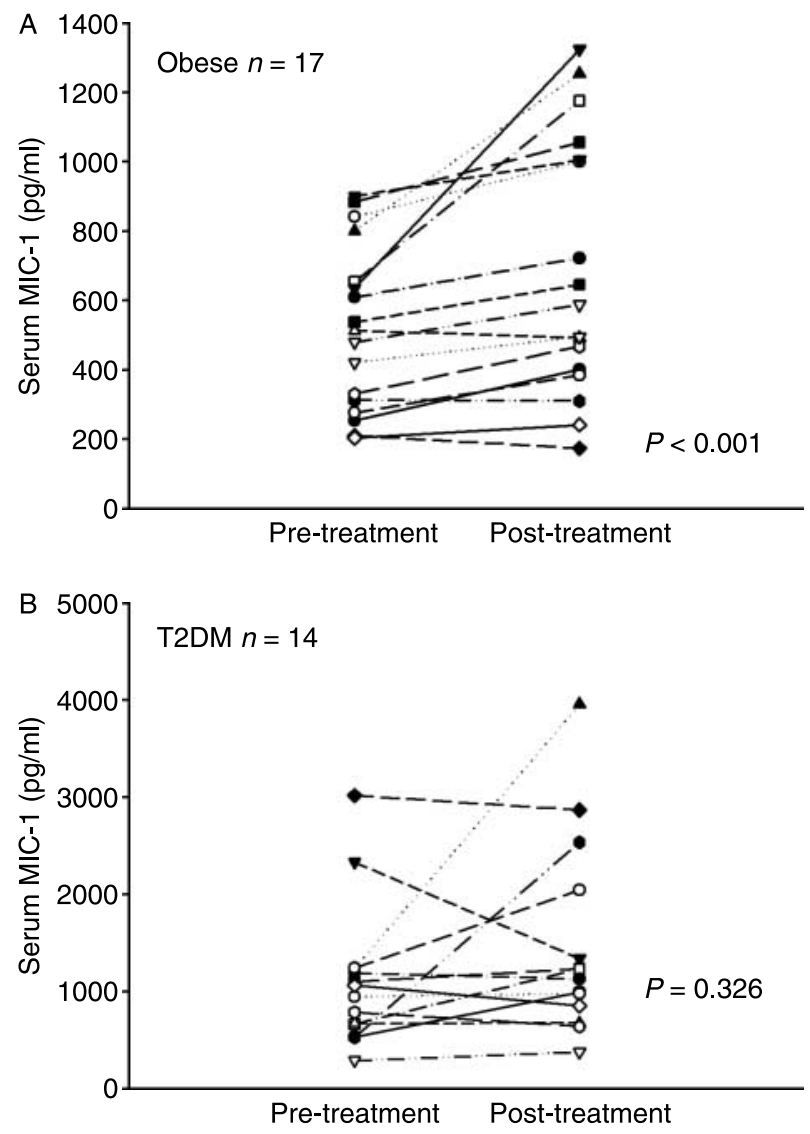

Figure 2 ( $A$ and $B$ ) The effect of 2 weeks of very low calorie diet $(550 \mathrm{kcal} /$ day) on serum concentrations of macrophage inhibitory cytokine-1 (MIC-1; pg/ml) in obese women without type 2 diabetes (A) and in obese women with type 2 diabetes (B). Statistical significance is from paired $t$-test. 
$(P=0.03)$ and serum CRP $(P=0.045)$ were independent predictors of serum MIC-1 levels.

In the population of obese women, both pre- and postVLCD MIC-1 significantly positively correlated with preVLCD serum triglycerides, pre- and post-VLCD serum glucose, and serum HbAlc. Pre-VLCD serum MIC-1 significantly positively correlated with pre-VLCD HOMA index in the population of obese women with/or without T2DM (Table 4). Delta MIC-1 during VLCD significantly positively correlated with delta serum insulin and delta HOMA index during VLCD (Table 4).

\section{MIC-1 mRNA expression in the subcutaneous and visceral adipose tissue of lean and nondiabetic obese women}

MIC-1 mRNA expression was detectable in both subcutaneous and visceral adipose tissue. Fat MIC-1 mRNA expression did not significantly differ between lean and obese women but it was significantly higher in subcutaneous than in visceral fat in both groups (Fig. 3).

MIC-1 mRNA expressions in both subcutaneous and visceral adipose depots significantly positively correlated with serum triglyceride levels. MIC-1 mRNA expression in visceral fat depot was significantly positively related to age (Table 5).

\section{Discussion}

The most important finding of the present study is that patients with obesity had significantly increased serum concentrations of MIC-1 relative to healthy normalweight women. The patients with combination of T2DM and obesity had further increased serum MIC-1 levels relative to the obese group despite comparable BMI, BF content, and inflammatory status. Circulating levels of MIC-1 were significantly increased by 2-week VLCD in obese women without T2DM while no significant change in this factor was found in the obese diabetic group.

The exact physiological role and the regulation of MIC-1 in humans are still only poorly understood. However, its biological character and current knowledge about its effects in humans suggested that it might play an important role in the development and progression of inflammatory and atherosclerotic

Table 4 Relationships of serum macrophage inhibitory cytokine-1 (MIC-1; pg/ml) with other anthropometric, hormonal, and biochemical parameters calculated in a combined population of all three study groups $(A, n=54)$ and in the combined group of obese patients (B and $C$, $n=31$ ) both before and after very low calorie diet program (VLCD).

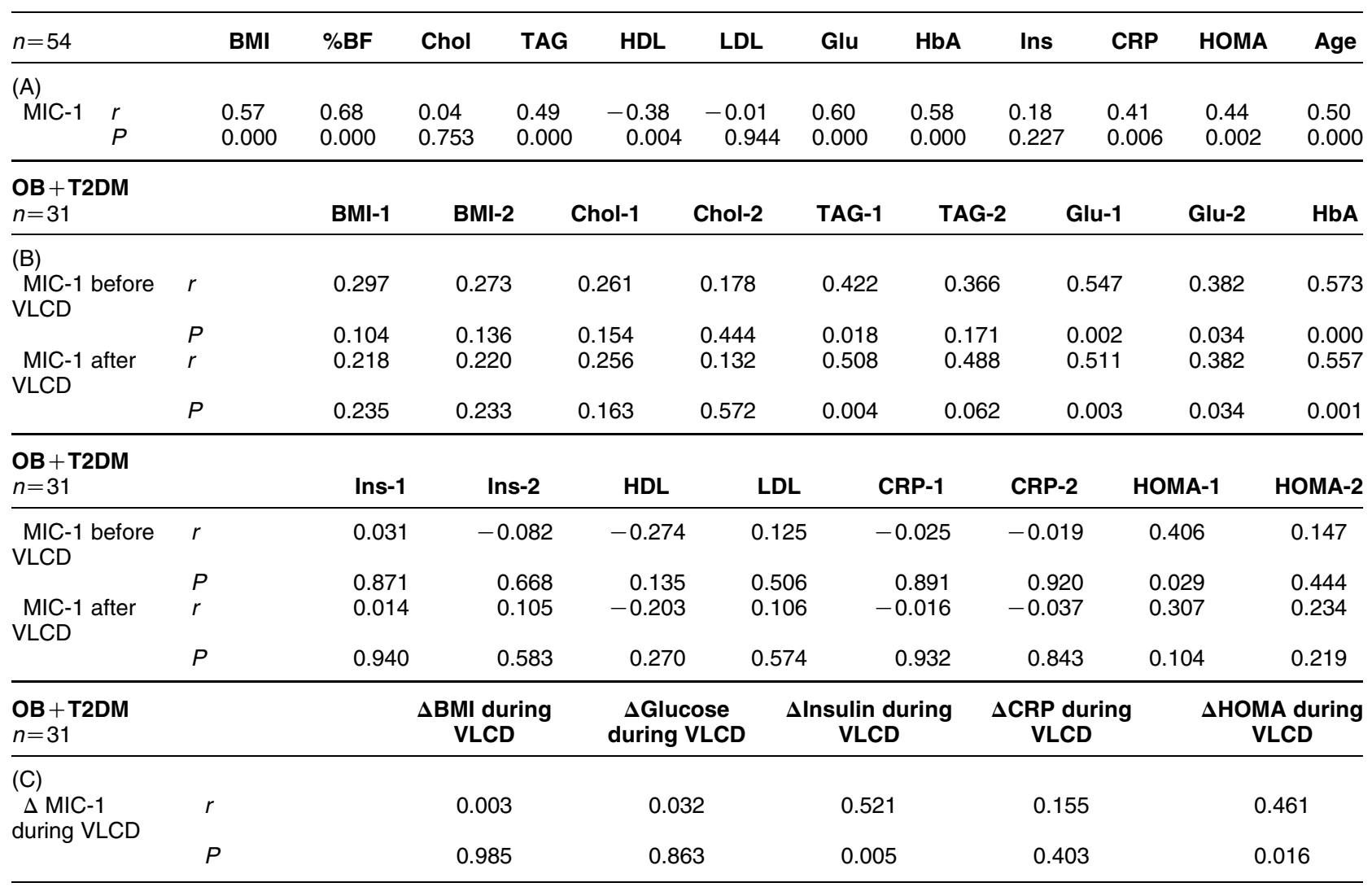

Results are from Spearman or Pearson Correlation Test as appropriate. BMI, body mass index; \%BF, percent body fat; chol, cholesterol; TAG, triglycerides; HDL, high-density lipoprotein cholesterol; LDL, low-density lipoprotein; glu, glucose; ins, insulin; CRP, C-reactive protein; HOMA, homeostasis model assessment of insulin resistance; 1 , before VLCD; 2 , after VLCD. 


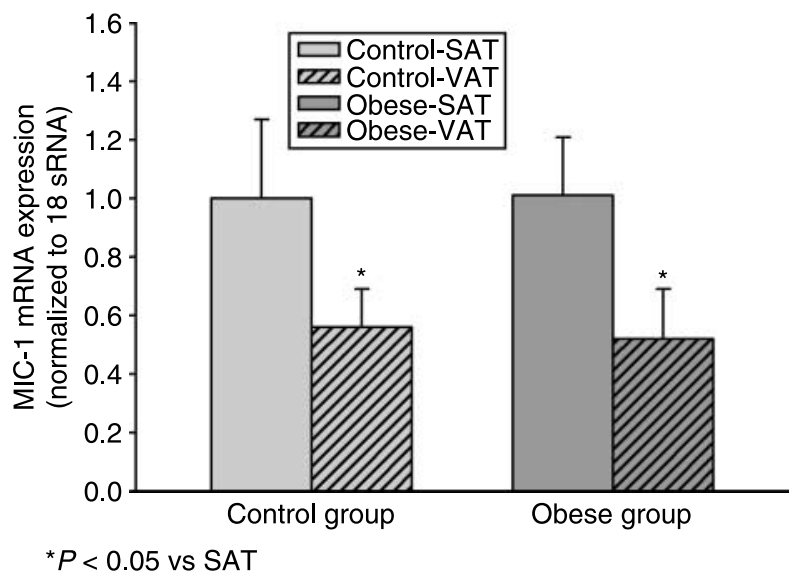

Figure 3 Relative expression of macrophage inhibitory cytokine-1 (MIC-1) in the subcutaneous (SAT) and visceral (VAT) adipose tissue of lean $(n=12)$ and nondiabetic obese women $(n=12)$. The expression of MIC-1 in the subcutaneous adipose tissue of lean women was taken as $100 \%$ or 1.0 respectively. Values are means \pm S.E.M. Statistical significance is from unpaired $t$-test.

processes and cancer $(7,10,12)$. Recent data indicated a direct role for MIC-1 in energy homeostasis regulation in cachectic conditions making it a potentially interesting candidate molecule to modulate food intake and/or body adiposity (14). Here, we show that human obesity is associated, similarly to cancer $(8-10)$ and inflammatory conditions of different etiology (7), with significantly higher serum MIC-1 levels. The fact that circulating MIC-1 levels are increased in both cachectic cancer patients and patients with obesity despite opposite changes in body weight and BF content argues rather against a direct role for body weight and $\mathrm{BF}$ content per se in the regulation of circulating MIC-1 levels. In a recently published paper, Ding et al. (16) demonstrated that MIC-1 mRNA expression was inversely related to BMI while in our group of patients we did not find such relationship. The reason for different findings between Ding's study and our data is not clear but it could have been due to different group of patients (different age range, combined population of males and females in Ding's study versus only female population in our study), concomitant medications or other reasons. In Ding's study, MIC-1 production in human adipocytes was stimulated by $\mathrm{H}_{2} \mathrm{O}_{2}$ indicating a possible involvement of oxidative stress in the induction of MIC-1 synthesis. Furthermore, 15d-prostaglandin $\mathrm{J}(2)$ has been reported to induce MIC-1 protein expression, promoting apoptosis in cancer cells (17) and the same was true for stimulation of MIC-1 production in human adipocytes in Ding's study. Taken together, these data suggest that oxidative stress might be an important inducer of MIC-1 production. The presence of increased oxidative stress $(18-20)$ could potentially explain why both cachectic and obese patients display increased MIC-1 levels. We suggest that both extreme cachexia in cancer patients and morbid obesity may result in nutritional stress and subsequently oxidative stress in adipocytes and other tissues which may in turn stimulate MIC-1 production. The cross-sectional design and other limitations of our study do not allow us to directly support this conclusion. Nevertheless, we have previously demonstrated that local changes in mRNA expression of some of the proinflammatory cytokines in subcutaneous adipose tissue of malnourished patients with anorexia nervosa share some similarities with changes in patients with obesity suggesting that local inflammatory response is present in adipose tissue of both cachectic and obese patients $(21,22)$.

Here, we showed that 2 weeks of VLCD did not significantly change serum MIC-1 levels in obese women with T2DM, but it significantly reduced serum MIC-1 in obese women without T2DM in spite of a similar reduction of body weight, serum cholesterol, serum triglycerides, and serum CRP during VLCD in both groups of patients. The reason for the differences between diabetic versus nondiabetic obese group could lie in the different metabolic flexibility between diabetic and nondiabetic patients. It has been shown that metabolic flexibility and response to various interventions such as VLCD is partially blunted in diabetic patients (23). Therefore, one possible explanation of lack of changes of MIC-1 levels in obese diabetic patients is that the intervention was not strong and long enough to induce appropriate global metabolic response in the diabetic group while it was able to do so in obese nondiabetic patients.

Collectively, our results indicate that the short-term regulation of MIC-1 may be influenced by long-term metabolic status and possibly also by oxidative stress

Table 5 Relationships of mRNA expression of macrophage inhibitory cytokine-1 (MIC-1) in subcutaneous (SAT) and visceral (VAT) adipose tissue with other anthropometric, hormonal, and biochemical parameters calculated in a combined population of lean and obese women $(n=24)$.

\begin{tabular}{|c|c|c|c|c|c|c|c|c|c|c|}
\hline & & MIC1 VAT & BMI & Age & CRP & Glu & Chol & TAG & Ins & HOMA \\
\hline MIC-1 & $r$ & 0.24 & 0.26 & 0.11 & 0.02 & -0.06 & 0.18 & 0.74 & 0.14 & 0.09 \\
\hline SAT & $P$ & 0.26 & 0.22 & 0.61 & 0.93 & 0.79 & 0.45 & 0.000 & 0.57 & 0.75 \\
\hline MIC-1 & $r$ & - & 0.15 & 0.61 & 0.12 & 0.13 & 0.03 & 0.55 & -0.09 & -0.23 \\
\hline VAT & $P$ & & 0.48 & 0.003 & 0.58 & 0.59 & 0.89 & 0.02 & 0.69 & 0.41 \\
\hline
\end{tabular}

Results are from Spearman or Pearson Correlation Test as appropriate. BMI, body mass index; chol, cholesterol; TAG, triglycerides; glu, glucose; ins, insulin; CRP, C-reactive protein; HOMA, homeostasis model assessment of insulin resistance. 
induced by various stimuli. For example, increased circulating MIC-1 levels may reflect p53 pathway activation (24). This pathway may, among other important functions, play a role in the pathophysiology of obesity (25). Furthermore, MIC-1 expression is one of genes responsible for initiating the process of stimulus-induced adaptive changes (26). Such a stimulus might be represented by receptor activation or cell stress such as the one induced by extreme nutritional changes.

The sites of MIC-1 production in humans are multiple and its relative significance under different pathophysiological conditions is mostly unknown $(1,4,5)$. Our results in a cross-sectional cohort of obese and lean women showed that MIC-1 is expressed in human adipose tissue with no significant difference between lean and obese subjects either in subcutaneous or in visceral adipose tissue. In agreement with the results of Ding et al. (16), we found significantly lower expression of MIC-1 in visceral than in subcutaneous fat in both lean and obese groups. Furthermore, we showed a significant relationship of MIC-1 mRNA expression in both adipose depots with circulating triglycerides suggesting a possible paracrine role of MIC-1 in adipose tissue metabolism (16). Our findings also indicated that the differences in circulating MIC-1 levels between the lean and the obese do not originate from differences in production in adipose tissue. It still remains to be determined whether activated macrophages, liver, adipose tissue, and/or other tissues are primary sources of MIC-1 in insulin resistant obese and/or diabetic subjects.

We are aware that our study has several limitations. One of these limitations is the difference in average age of diabetic group as compared with obese and control group. Although we did not find a significant relationship between circulating MIC-1 levels and age in the diabetic group of patients, we found such a relationship in a combined population of all three study groups. Furthermore, we found that visceral MIC-1 mRNA expression in a combined population of patients positively correlated with age. Therefore, the results of our study could have been partially influenced by this fact.

In conclusion, we demonstrated that serum MIC-1 concentrations are significantly increased in obese women relative to normal-weight healthy women. This increase was further augmented by the presence of T2DM. Our results also suggested different short-term nutritional regulation of MIC-1 in nondiabetic and diabetic obese subjects. We conclude that in contrast to cachectic cancer patients, elevated serum MIC-1 levels in patients with obesity or obesity and T2DM do not induce weight loss.

\section{Declaration of interest}

There is no conflict of interest.

\section{Funding}

This work was supported by MZOVFN2005.

\section{References}

1 Bootcov MR, Bauskin AR, Valenzuela SM, Moore AG, Bansal M, He XY, Zhang HP, Donnellan M, Mahler S, Pryor K, Walsh BJ, Nicholson RC, Fairlie WD, Por SB, Robbins JM \& Breit SN. MIC-1, a novel macrophage inhibitory cytokine, is a divergent member of the TGF-beta superfamily. PNAS 199794 11514-11519.

2 Paralkar VM, Vail AL, Grasser WA, Brown TA, Xu H, Vukicevic S, Ke HZ, Qi H, Owen TA \& Thompson DD. Cloning and characterization of a novel member of the transforming growth factor-beta/bone morphogenetic protein family. Journal of Biological Chemistry 1998273 13760-13767.

3 Hsiao EC, Koniaris LG, Zimmers-Koniaris T, Sebald SM, Huynh TV \& Lee SJ. Characterization of growth-differentiation factor 15 , a transforming growth factor beta superfamily member induced following liver injury. Molecular and Cellular Biology 2000 20 3742-3751.

4 Böttner M, Suter-Crazzolara C, Schober A \& Unsicker K. Expression of a novel member of the TGF-beta superfamily, growth/differentiation factor-15/macrophage-inhibiting cytokine-1 (GDF15/MIC-1) in adult rat tissues. Cell and Tissue Research 1999 297 103-110.

5 Kim KS, Baek SJ, Flake GP, Loftin CD, Calvo BF \& Eling TE. Expression and regulation of nonsteroidal anti-inflammatory drug-activated gene (NAG-1) in human and mouse tissue. Gastroenterology 2002122 1388-1398.

6 Bauskin AR, Brown DA, Junankar S, Rasiah KK, Eggleton S, Hunter M, Liu T, Smith D, Kuffner T, Pankhurst GJ, Johnen H, Russell PJ, Barret W, Stricker PD, Grygiel JJ, Kench JG, Henshall SM, Sutherland RL \& Breit SN. The propeptide mediates formation of stromal stores of PROMIC-1: role in determining prostate cancer outcome. Cancer Research 200565 2330-2336.

7 Brown DA, Moore J, Johnen H, Smeets TJ, Bauskin AR, Kuffner T, Weedon H, Milliken ST, Tak PP, Smith MD \& Breit SN. Serum macrophage inhibitory cytokine 1 in rheumatoid arthritis: a potential marker of erosive joint destruction. Arthritis and Rheumatism 200756 753-764.

8 Brown DA, Ward RL, Buckhaults P, Liu T, Romans KE, Hawkins NJ, Bauskin AR, Kinzler KW, Vogelstein B \& Breit SN. MIC-1 serum level and genotype: associations with progress and prognosis of colorectal carcinoma. Clinical Cancer Research 2003 9 2642-2650.

9 Brown DA, Stephan C, Ward RL, Law M, Hunter M, Bauskin AR, Amin J, Jung K, Diamandis EP, Hampton GM, Russell PJ, Giles GG \& Breit SN. Measurement of serum levels of macrophage inhibitory cytokine 1 combined with prostate-specific antigen improves prostate cancer diagnosis. Clinical Cancer Research 200612 89-96.

10 Koopmann J, Rosenzweig CN, Zhang Z, Canto MI, Brown DA, Hunter M, Yeo C, Chan DW, Breit SN \& Goggins M. Serum markers in patients with resectable pancreatic adenocarcinoma: macrophage inhibitory cytokine 1 versus CA19-9. Clinical Cancer Research 200612 442-446.

11 Brown DA, Breit SN, Buring J, Fairlie WD, Bauskin AR, Liu T \& Ridker PM. Concentration in plasma of macrophage inhibitory cytokine-1 and risk of cardiovascular events in women: a nested case-control study. Lancet $20023592159-2163$.

12 Bermúdez B, López S, Pacheco YM, Villar J, Muriana FJ, Hoheisel JD, Bauer A \& Abia R. Influence of postprandial triglyceride-rich lipoproteins on lipid-mediated gene expression in smooth muscle cells of the human coronary artery. Cardiovascular Research 200879 294-303. 
13 Zimmers TA, Jin X, Hsiao EC, McGrath SA, Esquela AF \& Koniaris LG. Growth differentiation factor-15/macrophage inhibitory cytokine-1 induction after kidney and lung injury. Shock $200523543-548$.

14 Johnen H, Lin S, Kuffner T, Brown DA, Tsai VW, Bauskin AR, Wu L, Pankhurst G, Jiang L, Junankar S, Hunter M, Fairlie WD, Lee NJ, Enriquez RF, Baldock PA, Corey E, Apple FS, Murakami MM, Lin EJ, Wang C, During MJ, Sainsbury A, Herzog H \& Breit SN. Tumor-induced anorexia and weight loss are mediated by the TGF-beta superfamily cytokine MIC-1. Nature Medicine 2007 13 1333-1340.

15 Matthews DR, Hosker JP, Rudenski AS, Naylor BA, Treacher DF \& Turner RC. Homeostasis model assessment: insulin resistance and beta-cell function from fasting plasma glucose and insulin concentrations in man. Diabetologia 198528 412-419.

16 Ding Q, Mracek T, Gonzalez-Muniesa P, Kos K, Wilding J, Trayhurn $\mathrm{P} \&$ Bing C. Identification of macrophage inhibitory cytokine- 1 in adipose tissue and its secretion as an adipokine by human adipocytes. Endocrinology $20091501688-1696$.

17 Baek SJ, Kim JS, Nixon JB, DiAugustine RP \& Eling TE. Expression of NAG-1, a transforming growth factor- $\beta$ superfamily member, by troglitazone requires the early growth response gene EGR-1. Journal of Biological Chemistry 2004279 6883-6892.

18 Fortunati N, Manti R, Birocco N, Pugliese M, Brignardello E, Ciuffreda L, Catalano MG, Aragno M \& Boccuzzi G. Pro-inflammatory cytokines and oxidative stress/antioxidant parameters characterize the bio-humoral profile of early cachexia in lung cancer patients. Oncology Reports $2007 \mathbf{1 8}$ 1521-1527.

19 Roberts CK \& Sindhu KK. Oxidative stress and metabolic syndrome. Life Sciences $2009 \mathbf{8 4} 705-712$.
20 Beattie JH, Wood AM, Newman AM, Bremner I, Choo KH, Michalska AE, Duncan JS \& Trayhurn P. Obesity and hyperleptinemia in metallothionein (-I and -II) null mice. PNAS 199895 358-363.

21 Dolezalova R, Lacinova Z, Dolinkova M, Kleiblova P, Haluzikova D, Housa D, Papezova $H$ \& Haluzik M. Changes of endocrine function of adipose tissue in anorexia nervosa: comparison of circulating levels versus subcutaneous mRNA expression. Clinical Endocrinology 200767 674-678.

22 Dolinková M, Dostálová I, Lacinová Z, Michalský D, Haluzíková D, Mráz M, Kasalický M \& Haluzík M. The endocrine profile of subcutaneous and visceral adipose tissue of obese patients. Molecular and Cellular Endocrinology 2008291 63-70.

23 Galgani JE, Moro C \& Ravussin E. Metabolic flexibility and insulin resistance. American Journal of Physiology. Endocrinology and Metabolism 2008295 E1009-E1017.

24 Yang H, Filipovic Z, Brown D, Breit SN \& Vassilev LT. Macrophage inhibitory cytokine-1: a novel biomarker for p53 pathway activation. Molecular Cancer Therapeutics 20032 1023-1029.

25 Yahagi N, Shimano H, Matsuzaka T, Najima Y, Sekiya M, Nakagawa Y, Ide T, Tomita S, Okazaki H, Tamura Y, Iizuka Y, Ohashi K, Gotoda T, Nagai R, Kimura S, Ishibashi S, Osuga J \& Yamada N. p53 Activation in adipocytes of obese mice. Journal of Biological Chemistry $200327825395-25400$.

26 Andreasson KI \& Kaufmann WE. Role of immediate early gene expression in cortical morphogenesis and plasticity. Results and Problems in Cell Differentiation 200239 113-137.

Received 18 May 2009

Accepted 7 June 2009 